\title{
Leishmanicidal activity of Cecropia pachystachya flavonoids: Arginase inhibition and altered mitochondrial DNA arrangement
}

\author{
Ebenézer de Mello Cruz ${ }^{a}$, Edson Roberto da Silva ${ }^{b, *}$, Claudia do Carmo Maquiaveli ${ }^{c}$, \\ Eliomara Sousa Sobral Alves ${ }^{\mathrm{a}}$, João Francisco Lucon Jr. ${ }^{\mathrm{d}}$, Matheus Balduino Gonçalves dos Reis ${ }^{\mathrm{b}}$, \\ Cleyton Eduardo Mendes de Toledo ${ }^{\mathrm{e}}$, Frederico Guaré Cruz $^{\mathrm{f}}$, Marcos André Vannier-Santos ${ }^{\mathrm{a}}$

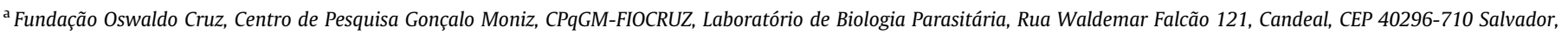 \\ BA, Brazil

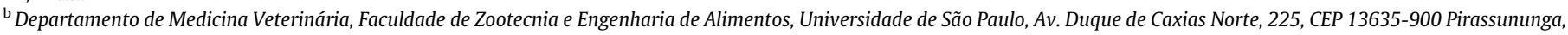 \\ SP, Brazil

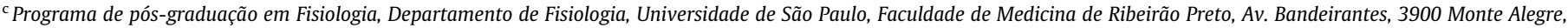 \\ CEP 14049-900 Ribeirão Preto, SP, Brazil \\ d Programa de pós-graduação em Zootecnia, Faculdade de Zootecnia e Engenharia de Alimentos, Universidade de São Paulo, Av. Duque de Caxias Norte, 225, CEP 13635-900 \\ Pirassununga, SP, Brazil \\ e Unidade de Ensino Superior Ingá, Curso de Farmácia, Av. Colombo, 9727 KM 130, 87070-000 Maringa, PR, Brazil \\ ${ }^{\mathrm{f}}$ Universidade Federal da Bahia, Instituto de Química, Departamento de Química Orgânica, UFBA, Campus de Ondina, CEP $40170-290$ Salvador, BA, Brazil
}

\section{A R T I C L E I N F O}

Article history:

Received 9 March 2012

Received in revised form 12 January 2013

Available online 1 March 2013

\section{Keywords:}

Cecropia pachystachya

Cecropiaceae

Arginase

Polyamines

Oxidative stress

Kinetoplast

Ultrastructure

Leishmania

\begin{abstract}
A B S T R A C T
The plant Cecropia pachystachya Trécul is widely used in Brazilian ethnomedicine to treat hypertension, asthma, and diabetes. Arginase is an enzyme with levels that are elevated in these disorders, and it is central to Leishmania polyamine biosynthesis. The aims of this study were to evaluate antileishmanial activity and inhibition of the arginase enzyme by $C$. pachystachya extracts, and to study changes in cellular organization using electron microscopy. The ethanol extract of $C$. pachystachya was tested on Leishmania (Leishmania) amazonensis promastigote survival/proliferation and arginase activity in vitro. Qualitative ultrastructural analysis was also used to observe changes in cell organization. The major bioactive molecules of the ethanol extract were characterized using liquid chromatography-electrospray ionizationmass spectrometry (LC-ESI-MS). The ethyl acetate fraction of the ethanol extract diminished promastigote axenic growth/survival, inhibited arginase activity, and altered a mitochondrial kinetoplast DNA (K-DNA) array. The bioactive compounds of $C$. pachystachya were characterized as glucoside flavonoids. Orientin (9) (luteolin-8-C-glucoside) was the main component of the methanol-soluble ethyl acetate fraction obtained from the ethanol extract and is an arginase inhibitor $\left(\mathrm{IC}_{50} 15.9 \mu \mathrm{M}\right)$. The ethyl acetate fraction was not cytotoxic to splenocytes at a concentration of $200 \mu \mathrm{g} / \mathrm{mL}$. In conclusion, C. pachystachya contains bioactive compounds that reduce the growth of $L$. (L.) amazonensis promastigotes, altering mitochondrial K-DNA arrangement and inhibiting arginase.
\end{abstract}

(c) 2013 Elsevier Ltd. All rights reserved.

\section{Introduction}

Leishmaniasis is a debilitating and potentially fatal parasitic disease that currently affects at least 12 million people, with an estimated incidence of 2 million new annual cases (ca. 1.5 million cases of cutaneous leishmaniasis and 500,000 of visceral form) in 88 countries (WHO, 2011). The current chemotherapeutic treatment is often associated with severe side-effects and refractory

\footnotetext{
* Corresponding author.

E-mail addresses: edsilva@usp.br, edson.silva@pq.cnpq.br (E.R. da Silva),cmaquiaveli@usp.br (Claudia do Carmo Maquiaveli), lucon@usp.br (J.F. Lucon Jr.), cemtoledo@hotmail.com (Cleyton Eduardo Mendes de Toledo), fguare@ufba.br (F.G. Cruz), vannier@bahia.fiocruz.br (M.A. Vannier-Santos).
}

cases (Astelbauer and Walochnik, 2011). The search for new therapeutic targets led to characterization of arginase from Leishmania (Leishmania) mexicana (Roberts et al., 2004), Leishmania (Leishmania) amazonensis (da Silva et al., 2008) and Leishmania (Leishmania) major (Reguera et al., 2009). Arginase is a manganese metalloenzyme that catalyzes the hydrolysis of L-arginine to Lornithine and urea. Ornithine is decarboxylated into putrescine, the diamine precursor of polyamines (PA) that is involved in many different mechanisms required for cell proliferation, and is thus a valuable target for antiparasitic chemotherapy (Birkholtz et al., 2011). Leishmania arginase knockouts have shown that the enzyme plays a central role in PA biosynthesis (Reguera et al., 2009; Roberts et al., 2004). The PA spermidine is required for trypanothione (N1,N8-bis(glutathionyl)spermidine) synthesis in trypanosomatid 
<smiles>O=c1cc(-c2ccc(O)cc2)oc2cc(O)cc(O)c12</smiles>

apigenin (1)<smiles>O=C(/C=C/c1ccc(O)c(O)c1)OC1CC2(O)CC(O)C1C(O)C2O</smiles>

chlorogenic acid (4)<smiles>O=c1c(O[C@@H]2O[C@H](CO)[C@@H](O)[C@H](O)[C@H]2O)c(-c2ccc(O)c(O)c2)oc2cc(O)cc(O)c12</smiles>

isoquercitrin (7)<smiles>O=c1cc(-c2ccc(O)c(O)c2)oc2c(C3OC(CO)C(O)C(O)C3O)c(O)cc(O)c12</smiles>

orientin (2)<smiles>Oc1cc(O)c2c(c1)OC(c1ccc(O)c(O)c1)C(O)C2</smiles>

(+)-catechin (5)<smiles>O=c1cc(-c2ccc(O)c(O)c2)oc2cc(O)cc(O)c12</smiles>

luteolin (8)<smiles>O=c1cc(-c2ccc(O)cc2)oc2cc(O)c(O)c(C3OC(CO)[C@@H](O)[C@@H](O)[C@H]3O)c12</smiles>

Isovitexin (3)<smiles>Oc1cc(O)c2c(c1)O[C@H](c1ccc(O)c(O)c1)[C@H](O)C2</smiles>

(-)-epicatechin (6)

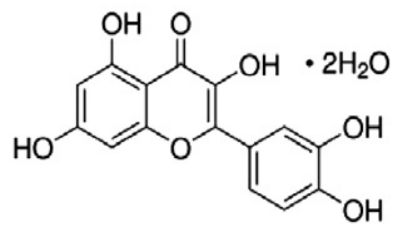

quercetin (9)

Fig. 1. Compounds 1-9.

parasites such as Leishmania. This molecule scavenges reactive oxygen (Fairlamb and Cerami, 1992; Fonseca-Silva et al., 2011) and nitrogen species (Bocedi et al., 2010), protecting protozoa from endogenous and immune-response-derived oxidative stress.

Reduced PA synthesis and transport is implicated in mitochondrial damage and k-DNA disorganization in Trypanosoma cruzi (Menezes et al., 2006) and $L$. (L.) amazonensis (Vannier-Santos et al., 2008). To survive within macrophages, Leishmania uses arginase to drive the conversion of L-arginine to ornithine and to down-regulate the production of nitric oxide by inducible NO synthase (iNOS) (Gaur et al., 2007). TH1 cytokine-activated macrophages trigger iNOS to convert L-arginine to NO and citrulline, killing the parasites, whereas $\mathrm{TH} 2$ cytokines mediate macrophage arginase activation, providing ornithine to polyamine biosynthesis and enabling parasite survival and proliferation (Iniesta et al., 2002; Wanderley and Barcinski, 2010).

The use of $\mathrm{N}^{\omega}$-hydroxy-L-arginine (NOHA), a physiologic arginase inhibitor, can control Leishmania infection in a susceptible mice strain (Iniesta et al., 2001). In fact, NOHA can inhibit both host and Leishmania arginase, providing a rational target for the design of drugs to treat leishmaniasis (Riley et al., 2011).

Several Brazilian plants show ethnopharmacological activity against $L$. (L.) amazonensis promastigotes (de Toledo et al., 2011; Muzitano et al., 2009). The Cecropia genus is used in folk medicine to treat asthma and hypertension (Delarcina et al., 2007; LimaLandman et al., 2007; Tanae et al., 2007), diseases that are correlated with increased arginase activity and decreased production of NO, a potent bronchodilator and vasodilator (Bergeron et al., 2007; Demougeot et al., 2007). Previous work has shown that Cecropia pachystachya produces chlorogenic acid (4), (+)-catechin (5), (-)-epicatechin (6), isoquercitrin (7), isovitexin (3), isoorientin, orientin (2) and procyanidin B2 (Lacaille-Dubois et al., 2001) (Fig. 1). Both (+)-catechin (5) and (-)-epicatechin (6) were previously tested and shown to be microbicidal against Leishmania (Leishmania) donovani amastigotes (Tasdemir et al., 2006). In this work, the $C$. pachystachya extract was studied as well as its fractions and isolated compounds, for activity against $L$. (L.) amazonensis arginase. It is demonstrated here that the compound orientin (2) in the ethyl acetate fraction of the $C$. pachystachya ethanolic extract is leishmanicidal, inhibiting arginase and altering parasite mitochondrial K-DNA organization.

\section{Results}

\subsection{Activity of the C. pachystachya extract on arginase activity}

At a concentration of $10 \mu \mathrm{g} / \mathrm{mL}$, the ethanol extract (EE) inhibited $90 \%$ of $L$. ( $L$.) amazonensis arginase activity. DFMO ( $\alpha$-difluormethylornithine), a selective irreversible ornithine decarboxylase inhibitor, was then used for a comparison with other polyamine pathway antagonists; DFMO caused 30\% inhibition of arginase activity at $218.6 \mu \mathrm{g} / \mathrm{mL}(1 \mathrm{mM})$. The $\mathrm{IC}_{50}$ values for the ethyl acetate fraction $(\mathrm{AF})$, which was divided into methanol-soluble (AF$\mathrm{MS}$ ), methanol-insoluble (AF-MI), $n$-butanol (BUF) and dichloromethane fractions (DFs), are presented in Table 1.

\subsection{Characterization of the $A F-M S$}

Analysis of AF-MS by LC-ESI-MS showed four predominant symmetrical peaks using UV detection and +MS (Fig. 2). The retention times (RT) observed $(280 \mathrm{~nm})$ were 13.2, 15.0, 16.1 and 
Table 1

Inhibition of arginase and promastigotes growth by extract fractions derived from the EE through fractionation of the organic phase.

\begin{tabular}{lcl}
\hline Fraction $^{\mathrm{a}}$ & $\mathrm{IC} \mathrm{C}_{50} \pm \mathrm{SE}(\mu \mathrm{g} / \mathrm{mL})$ & \\
\cline { 2 - 3 } & Arginase inhibition & Promastigotes growth \\
\hline $\mathrm{AF}$ & $17 \pm 2$ & $53.3 \pm 6.4$ \\
$\mathrm{AF}-\mathrm{MS}$ & $48 \pm 4$ & $\mathrm{nd}^{\mathrm{b}}$ \\
$\mathrm{AF}-\mathrm{MI}$ & $64 \pm 7$ & $\mathrm{nd}$ \\
$\mathrm{BUF}$ & $90 \pm 11$ & $24.8 \pm 1.7$ \\
$\mathrm{DF}$ & $200 \pm 25$ & $5.6 \pm 0.5$ \\
\hline
\end{tabular}

${ }^{a}$ AF, ethyl acetate fraction; MS, methanol-soluble; MI, methanol-insoluble; BUF, n-butanol fraction; DF, dichloromethane fraction.

$\mathrm{b}$ nd, not determined.

16.8 min using an Ascentis RP-Amide column, and the $[\mathrm{M}+\mathrm{H}]^{+}$values for these compounds were $m / z 581,449,595$ and 565 , respectively. The relative abundance for these major four peaks, obtained by integration of peaks and assessed by UV detection, were $13.8 \%$, $23.6 \%, 13.5 \%$ and $16.6 \%$ for $m / z 581,449,595$ and 565 , respectively.

The UV/Vis spectrum shows that the four compounds had broad bands of absorption, with maximum peaks at $\lambda=350 \mathrm{~nm}$ (peak 2, 3 and 4) and $338 \mathrm{~nm}$ (peak 5) that are characteristic of flavonoids (Fig. 3). The second narrow absorption band at $270 \mathrm{~nm}$ was characteristic of apigenin (1) (Fig. 1) and can be observed in peak 5 of the chromatogram (Fig. 2). Peak 3 with $\mathrm{m} / z 449$ (RT 14.9 min) was identified as orientin (2) by comparison with RT, UV and mass spectra of an authentic sample. Peak 6 (lower intensity) with $\mathrm{m} / \mathrm{z}$ 433 (RT 19.35) was identified as isovitexin (3) (apigenin-6-C-glucoside) by comparison with its RT, UV and mass spectra to an authentic sample. Data for the authentic samples of orientin (2) and isovitexin (3) were collected separately and compared to data collected for the extract (Table 2).

\subsection{Arginase inhibition by natural compounds}

Chlorogenic acid (4), (+)-catechin (5), (-)-epicatechin (6), and isoquercitrin (7) showed inhibitions above $50 \%$ at $20 \mu \mathrm{M}$ (Table 3). Orientin (2) exhibited an $\mathrm{IC}_{50}$ of $7 \mu \mathrm{g} / \mathrm{mL}(16 \mu \mathrm{M})$, while the $\mathrm{IC}_{50}$ for the AF-MS, which contained approximately $24 \%$ orientin (2), was $48 \mu \mathrm{g} / \mathrm{mL}$. Thus, orientin (2) contributes significantly to arginase inhibition by AF-MS. All inhibition experiments were conducted at $\mathrm{pH} 9.5$ because arginase activity drops off steeply at $\mathrm{pH} 7.5$ (Riley et al., 2011).

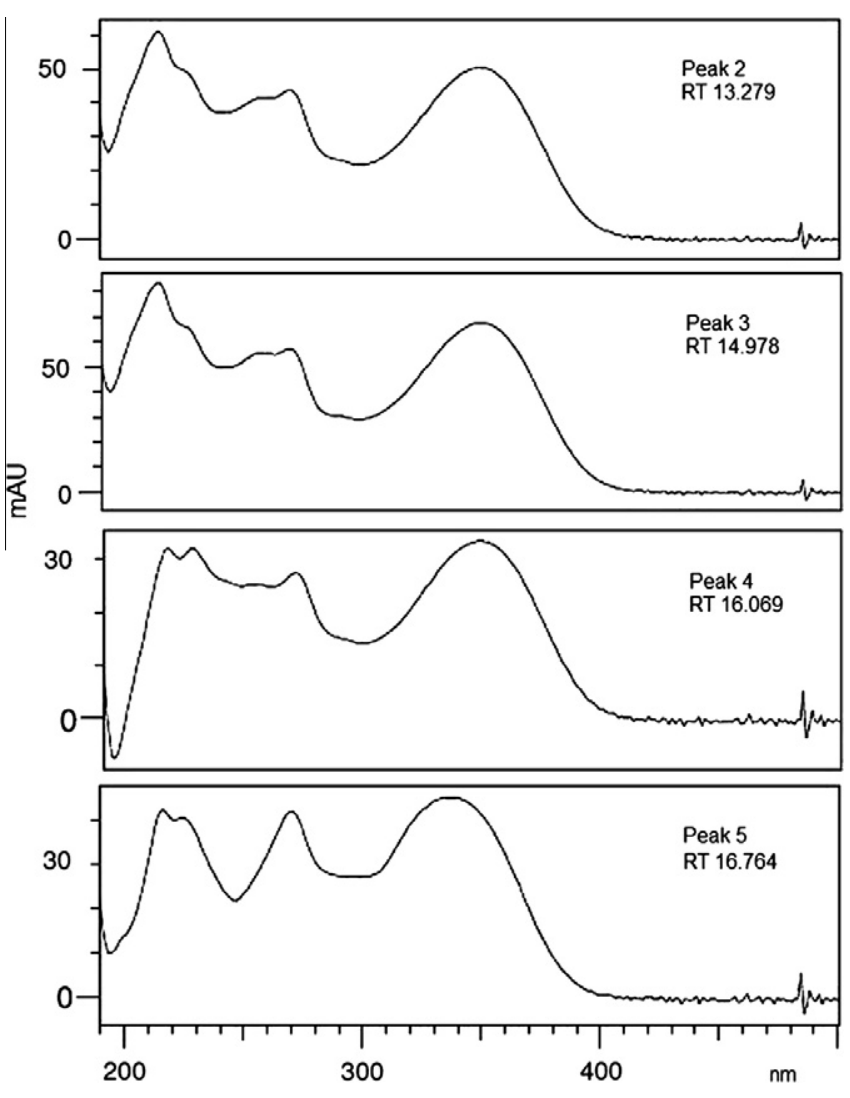

Fig. 3. UV-Vis spectra of the major constituents of AF-MS. (RT = retention time in minutes).

2.4. Ultrastructural changes in promastigote cells of $L$. (L.) amazonensis caused by the AF-MS fraction of C. pachystachya extract

The AF-MS was tested in a $100 \mu \mathrm{g} / \mathrm{mL}$ culture of promastigote cells of $L$. (L.) amazonensis and inhibited $70 \%$ of parasite growth in $96 \mathrm{~h}$. An incubation time of $72 \mathrm{~h}$ was therefore used to better assess early changes in the parasite. In ultrastructural qualitative evaluation of $L$. (L.) amazonensis promastigotes, it was observed that control cells remained intact, with characteristic organelles including the single mitochondrion that spans the entire cell and contains the kinetoplast (Fig. 4A). In the analysis of cells treated

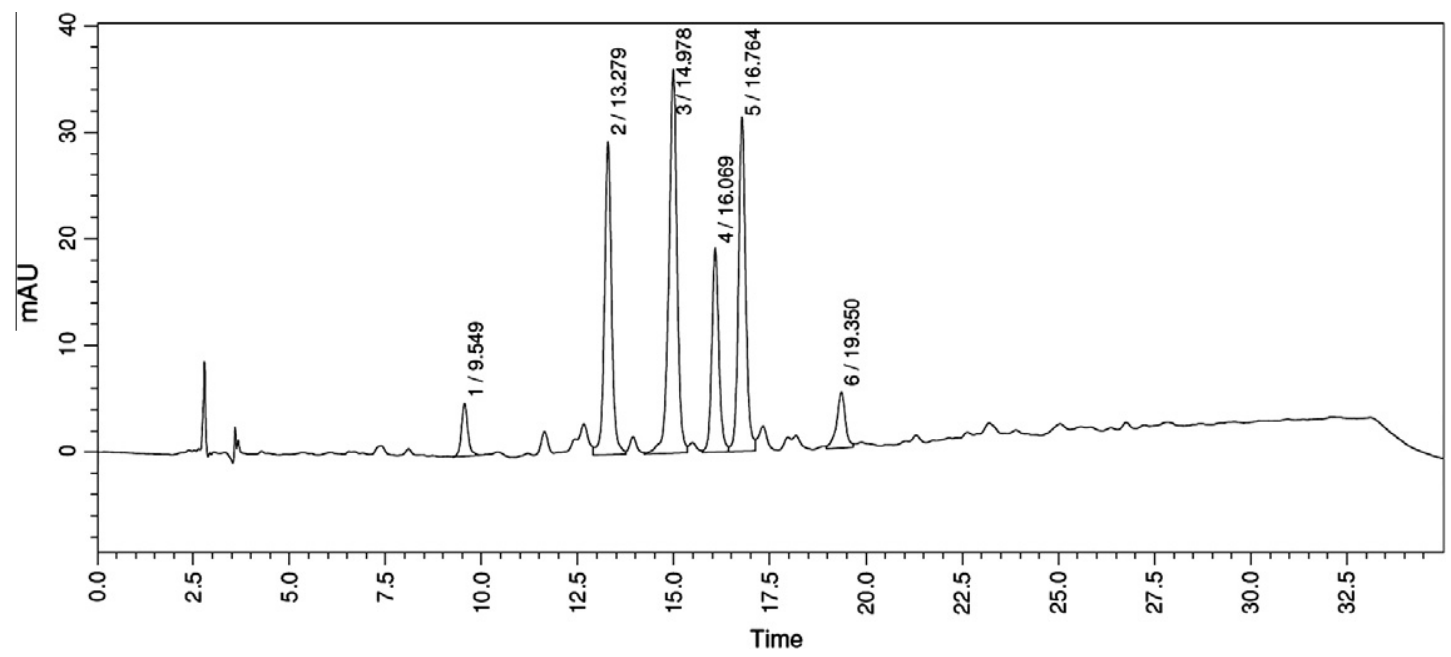

Fig. 2. Analysis of the AF-MS by LC-ESI-MS using an RP-amide column. The chromatogram shows absorbance at $280 \mathrm{~nm}$. 
Table 2

Active compounds identified from the AF-MS.

\begin{tabular}{llcl}
\hline$m / z[\mathrm{M}-\mathrm{H}]^{+}$ & Peak/RT $(\mathrm{min})$ & UV peaks $(\mathrm{nm})$ & Compound \\
\hline 449 & $3 / 14.978$ & $257,270,350$ & $\begin{array}{l}\text { Orientin }(\mathbf{2}) \\
\text { (luteolin-8-C-glucoside) }\end{array}$ \\
433 & $6 / 19.350$ & 270,338 & $\begin{array}{l}\text { Isovitexin (3) } \\
\text { (apigenin-6-C-glucoside) }\end{array}$ \\
\hline
\end{tabular}

Table 3

Inhibition of arginase by natural compounds at $20 \mu \mathrm{M}$.

\begin{tabular}{ll}
\hline Compound & Inhibition \pm SE $(\%)$ \\
\hline Chlorogenic acid (4) & $67 \pm 5$ \\
(+)-Catechin (5) & $66 \pm 8$ \\
(-)-Epicatechin (6) & $62 \pm 7$ \\
Isoquercitrin (7) & $54 \pm 6$ \\
Isovitexin (3) & $14 \pm 3$ \\
\hline
\end{tabular}

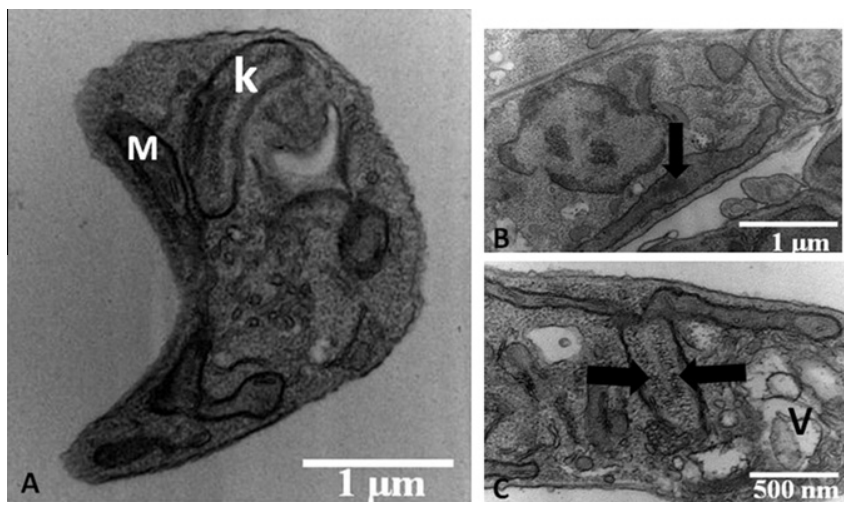

Fig. 4. Transmission electron microscopy of $L$. (L.) amazonensis promastigotes after treatment with $100 \mu \mathrm{g} / \mathrm{mL}$ ethyl acetate extract for $72 \mathrm{~h}$. (A) Untreated control displaying a single mitochondrion (M) with kinetoplast (K). (B) Treated cells showing swollen mitochondria with electrodense matrix deposits (arrow). (C) Treated cells showing kinetoplasts with two k-DNA masses in a parallel arrangement (arrows). Treated parasites also presented cytoplasmic vacuolization (V). $(\mathrm{N}=$ nucleus $)$

with $100 \mu \mathrm{g} / \mathrm{mL}$ AF-MS, swollen mitochondria were observed displaying electrondense concretions in the matrix (Fig. 4B) and changes in the arrangement of k-DNA in the kinetoplast (Fig. 4C).

\subsection{Antileishmanial susceptibility}

Antileishmanial activity was evaluated for the three fractions derived from EE (Table 1 ). The lowest $\mathrm{IC}_{50}$ was obtained with the dichloromethane following $n$-butanol and ethyl acetate fractions. The differences of the $\mathrm{IC}_{50}$ between fractions was significant $(p<0.05)$.

\subsection{Toxicity to splenocytes}

The toxicity of the AF was evaluated in splenocyte cultures at 200, 100, 50 and $25 \mu \mathrm{g} / \mathrm{mL}$ (Fig. 5). There were no significant changes in cell viability at the concentrations used $(p>0.05)$.

\section{Discussion}

Polyamine metabolic pathways furnish promising drug targets and strategies for parasitic diseases caused by protozoa such as Leishmania spp. (Birkholtz et al., 2011). The arginase knockouts of L. (L.) mexicana (Roberts et al., 2004), L. (L.) major (Reguera et al., 2009) and $L$. (L.) amazonensis (da Silva et al., 2012b) demonstrated the importance of the enzyme for the growth of the parasite. This
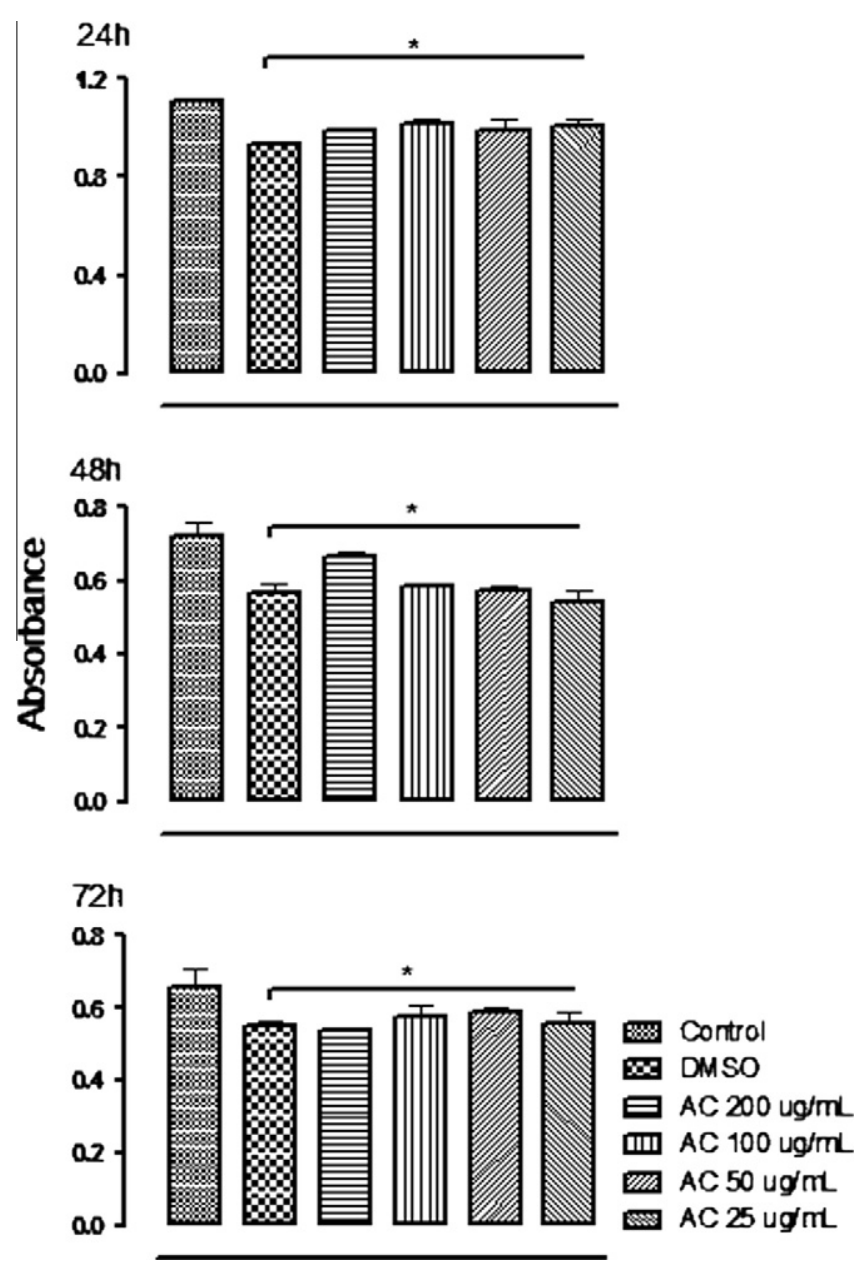

Fig. 5. Assessment of toxicity to splenocytes using the MTT method in the presence of different ethyl acetate extracts concentrations for 24,48 and $72 \mathrm{~h}$. AC = acetate fraction ${ }^{*} p>0.05$.

enzyme plays a pivotal role in PA biosynthesis and pathogenesis (Balaña-Fouce et al., 2012). Promastigotes display arginine transporters that sense the amino acid pools (Castilho-Martins et al., 2011).

Comparative molecular modeling showed differences in the vicinity of the active site between the human and $L$. (L.) amazonensis enzymes (da Silva et al., 2002). Synthetic inhibitors not only are not selective for $L$. (L.) mexicana arginase, but also inhibit the parasite growth with a potency lower than the inhibition of the parasite enzyme (Riley et al., 2011).

Cecropia extracts constitute a valuable tool in the search for antiparasitic drugs, as species of this genus have been reported in ethnopharmacological studies to be cardiotonic, diuretic, hypotensive, anti-inflammatory, hypoglycemic and anti-asthmatic (Aragão et al., 2010; Consolini et al., 2006; Schinella et al., 2008). These extracts have been particularly of interest for treatment of leishmaniasis (Odonne et al., 2011). All fractions derived from $C$. pachystachya extract showed $\mathrm{IC}_{50}$ lower than pentostam $\left(\mathrm{IC}_{50}>\right.$ $64 \mu \mathrm{g} \mathrm{Sb} / \mathrm{mL}$ ) against promastigotes, but showed lower potency than amphotericin ( $\mathrm{IC}_{50} 0.65 \mu \mathrm{g} / \mathrm{mL}$ ) and miltefosine ( $\mathrm{IC}_{50} 0.6 \mu \mathrm{g} /$ $\mathrm{mL}$ ) (Vermeersch et al., 2009). The fraction AF showed an $\mathrm{IC}_{50}$ against promastigotes of the $53 \mu \mathrm{g} / \mathrm{mL}$, while IC $_{50}$ for arginase inhibition was $17 \mu \mathrm{g} / \mathrm{mL}$. The difference between the inhibitory action of $\mathrm{AF}$ on the arginase and the parasite may be due to the access of drugs to the glycosome, the organelle where arginase is located in the parasite (da Silva et al., 2012b). No genotoxic effects were associated with Cecropia obtusifolia (Toledo et al., 2008), which suggests the possibility of developing innovative non-toxic drugs. 
Here, the action of a plant extract rich in flavonoids is described that inhibits arginase and is active against $L$. (L.) amazonensis promastigotes (Table 1 ). In studies of the quantitative structure-activity relationship, flavonoids were tested on cultures of $L$. (L.) donovani, Trypanosoma brucei rhodesiense and T. cruzi (Tasdemir et al., 2006); most compounds tested had greater activity against $L$. $(L$.) donovani and $T$. brucei rhodesiense. Species of the genus Leishmania (Camargo et al., 1978) and T. brucei rhodesiense (Heby et al., 2007), but not $T$. cruzi, express arginase (Camargo et al., 1978). Flavonoids such as luteolin (8) and quercetin (9) cause apoptosis by inducing cleavage of kinetoplast DNA mediated by topoisomerase II, as previously reported (Mittra et al., 2000). Quercetin $(\mathbf{9})$ has been characterized as an inhibitor of arginase (da Silva et al., 2012a) and ribonucleotide reductase (Sen et al., 2008). Quercetin (9) is also able to chelate $\mathrm{Mn}^{2+}$ (cofactor of arginase), inducing cleavage of plasmid DNA (Jun et al., 2007) and $\mathrm{Fe}^{+2}$ and causing a decrease in the supply of iron needed for the development of $L$. $(L$.) donovani (Sen et al., 2008). Inhibition of arginase blocks the first step of the synthesis of polyamines that are essential for the multiplication and maintenance of the antioxidant mechanism through synthesis of trypanothione (Colotti and Ilari, 2011). Here, it was shown that an ethanol extract fractionated with ethyl acetate resulted in an enriched flavonoid fraction soluble in methanol, which largely shows the presence of six natural products possibly derived from luteolin $(\mathbf{8})$ and apigenin (1). One of the four major components was identified as orientin (2); the other related compounds were the product of conjugations of apigenin (1) or luteolin (8) with glucose, xylose and arabinose. Apigenin-7-O-glucoside, luteolin-5-O-glucoside, and luteolin-7-0-glucoside have shown high activity against amastigotes from $L$. (L.) donovani (Tasdemir et al., 2006).

The toxicity of the ethyl acetate fraction was tested in splenocytes and showed no significant change to cell cultures. In this work, it was shown that arginase from Leishmania is a target for C. pachystachya flavonoids. The lack of cell toxicity in splenocytes and selectivity for parasite enzymes are important parameters for the development of selective inhibitors. Thus, the components of the ethyl acetate fraction of the ethanolic extract of $C$. pachysyachya did not affect the host, while showing good activity against promastigotes of Leishmania at $100 \mu \mathrm{g} / \mathrm{mL}$, the concentration that reduced the growth of parasites by $70 \%$ in $96 \mathrm{~h}$. Flavonoids can contribute to reduced PA synthesis and consequently down-modulate the parasite antioxidant system, triggering oxidative stress and apoptosis. However, the activity of arginase at near-neutral $\mathrm{pH}$ drops steeply (Riley et al., 2011), and the activity and inhibition of arginase is not detected in vitro. At pH 9.5, the flavonoids did not inhibit rat liver arginase, used as a mammalian enzyme model, but instead showed selective inhibition of protozoan enzymes.

Electron microscopy approaches have provided valuable data in the elucidation of mechanisms of action of antiparasitic compounds (Vannier-Santos and De Castro, 2009; Vannier-Santos and Lins, 2001; Vannier-Santos et al., 2008). Kinetoplast segregation precedes the onset of nuclear division, and the elongated kDNA is usually slightly rotated or tilted during division (Ambit et al., 2011), but not arranged in a parallel array as reported here. This configuration presumably precludes the segregation driven by side-by-side basal bodies. It is therefore noteworthy that protozoa cell-cycle machinery may be a target in antiparasitic chemotherapy (Hammarton et al., 2003). Here, it was shown mitochondrial damage and kDNA disorganization by transmission electron microscopy. These alterations maybe due to PA deficiency, as these polycations are antioxidant (Maia et al., 2008; Menezes et al., 2006; Tkachenko et al., 2011; Vannier-Santos et al., 2008) and can stabilize and regulate the function of nucleic acids (Igarashi and Kashiwagi, 2010). Such an inference is in agreement with that previously demonstrated by the effect of reduced PA synthesis in Trypanosoma cruzi (Menezes et al., 2006) and L. (L.) amazonensis
(Vannier-Santos et al., 2008). Polyamine depletion also leads to the destruction of Tritrichomonas foetus hydrogenosomes (Reis et al., 1999), the redox organelles inside anaerobic trichomonad parasites. Parasite cytoplasmic vacuolation may be caused by autophagic triggering due to oxidative stress (Menezes et al., 2006; Vannier-Santos et al., 2008).

Pleiotropic drugs against cancer, cardiovascular and parasitic diseases have been considered by several researchers (Cavalli et al., 2010; Frantz, 2005; Hampton, 2004). Considered as multitarget compounds against Leishmania and Trypanosoma (Cavalli et al., 2010), the flavonoids can comprise multifunctional drugs or can be used as lead compounds in multifunctional drug design schemes. The biodiversity of flavonoids can contribute to research based on the mechanism of action of isolated or mixed flavonoids on multiple targets related to leishmaniasis.

\section{Conclusion}

Analysis by transmission electron microscopy showed that the C. pachystachya extract rearranged mitochondrial DNA, which can lead to interference with the negative modulation of polyamines and trypanothione biosynthesis. This effect is relevant because Leishmania arginase has been implicated in the maintenance of infection in mammalian hosts, and flavonoids presents in the ethyl acetate fraction, orientin (2) and isovitexin (3), might be used as prototypes for rational drug design or as part of a multidrug treatment for leishmaniasis.

\section{Experimental}

\subsection{Extract and fractions}

Leaves of C. pachystachya were collected in February 2008 on the Ondina Campus of the Federal University of Bahia - UFBA, Salvador, Bahia, Brazil. Taxonomic identification was made by Dr. Maria L.S. Guedes, Biology Institute - UFBA. The voucher specimen is deposited in the Herbarium Alexandre Leal Costa - Biology Institute - UFBA as $n^{\circ} 82550$.

Leaves were washed in $\mathrm{H}_{2} \mathrm{O}$, superficially dried with absorbent paper, dried for 3 weeks at $25^{\circ} \mathrm{C}$ and ground in a mill (Thomas Wiley Laboratory Mill - Model 4). The extraction process was performed by exhaustive maceration of dry powdered leaves $(50 \mathrm{~g})$ in EtOH $(1 \mathrm{~L})$ with three changes of solvent, once every $48 \mathrm{~h}$ at $25^{\circ} \mathrm{C}$. The filtrate was concentrated in a rotary evaporator (BUCHI Model R-3000) under reduced pressure at $45^{\circ} \mathrm{C}$, to yield the crude ethanol extract (EE). Aliquots of the EE were resolubilized in EtOH, with subsequent addition of $\mathrm{H}_{2} \mathrm{O}-\mathrm{EtOH}(1: 4, \mathrm{v} / \mathrm{v})$ to perform the partition. The soluble fraction in EtOH: $\mathrm{H}_{2} \mathrm{O}(4: 1)$ was subjected to extraction with $n$-hexane to yield the hexane fraction (HF). The remaining phase in EtOH: $\mathrm{H}_{2} \mathrm{O}(4: 1)$ was extracted with $\mathrm{CH}_{2} \mathrm{Cl}_{2}$, to yield a $\mathrm{CH}_{2} \mathrm{Cl}_{2}$ soluble fraction (DF). After extraction with $\mathrm{CH}_{2} \mathrm{Cl}_{2}$, the remaining phase in EtOH: $\mathrm{H}_{2} \mathrm{O}(4: 1)$ was subjected to extraction with EtOAc, resulting in the EtOAc soluble fraction (AF). Finally, the remaining fraction was extracted with $n$-BuOH (BUF). Three partitions with each solvent were used at each stage, each with onethird of the total volume of the hydro-alcoholic phase. After evaporation of solvent under reduced pressure, each fraction was resuspended in $\mathrm{H}_{2} \mathrm{O}$, and the resulting solutions were used to determine the $\mathrm{IC}_{50}$.

\subsection{Characterization of the active constituents from C. pachystachya}

Characterization of the most active constituents from C. pachystachya was performed using liquid chromatography-mass spectra (LC-MS) using an Esquire 3000 Plus (Bruker Daltonics). Separation 
was performed using an RP-amide (Ascentis-Supelco, Sigma-Aldrich) column $(25 \mathrm{~cm} \times 4.6 \mathrm{~mm} ; 5 \mu \mathrm{M})$. Samples $(5 \mathrm{mg} / \mathrm{mL})$ were prepared in $0.1 \% \mathrm{HCOOH}$, and aliquots $(10 \mu \mathrm{L})$ were injected onto the column at a flow rate of $1 \mathrm{~mL} / \mathrm{min}$. The constituents were eluted using a linear gradient from $10 \%$ to $35 \% \mathrm{CH}_{3} \mathrm{CN}-\mathrm{H}_{2} \mathrm{O}$ containing $0.1 \% \mathrm{HCOOH}$ in $30 \mathrm{~min}$. Detection was carried out at $280 \mathrm{~nm}$ using diode array detection (DAD) and mass detection. The actives constituents were characterized by comparison with an authentic sample by the retention time (RT), mass spectra and UV-Vis spectra.

\subsection{Parasites}

The $\mathrm{MHOM} / \mathrm{Br} / 75 / \mathrm{Josefa}$ strain of $L$. (L.) amazonensis isolated from a human case of LCD in Brazil by Dr. CA Cuba-Cuba (University of Brasilia, Brazil) was maintained in axenic culture as promastigotes at $27{ }^{\circ} \mathrm{C}$ in Warren medium (broth infusion of bovine brain and heart, folic acid $20 \mathrm{mg} / \mathrm{L}$ and hemin $20 \mathrm{mg} / \mathrm{L}$ ) supplemented with $10 \%$ fetal bovine serum. To verify the leishmanicidal activity of the fractions, $5 \mathrm{~mL}$ cultures of stationary-phase promastigotes were centrifuged at $1000 \mathrm{~g}$ for $10 \mathrm{~min}$ at $27^{\circ} \mathrm{C}$. The pellet was resuspended in the medium $(1 \mathrm{~mL})$ and used to inoculate $5.0 \times 10^{5}$ parasites $/ \mathrm{mL}$ in $10 \mathrm{~mL}$ tubes with medium $(3 \mathrm{~mL})$. The growth of parasites in the absence or presence of inhibitors was assessed by direct counting using a Neubauer chamber under phase microscopy.

\subsection{Assessment of toxicity to splenocytes}

For experiments with splenocytes, BALB/c mice spleens were obtained to assess mitochondrial redox activity using methylthiazolyldiphenyl-tetrazolium bromide (MTT) test. Inocula of $1.0 \times 10^{7}$ splenocytes were incubated in 96-well plates with $200 \mu \mathrm{L}$ of RPMI (supplemented with $10 \%$ fetal bovine serum, $80 \mu \mathrm{g} / \mathrm{mL}$ gentamycin, $10 \mathrm{IU} / \mathrm{mL}$ penicillin and $10 \mu \mathrm{g} / \mathrm{mL}$ streptomycin) and either the extract or fractions. Cultures were incubated for 24,48 and $72 \mathrm{~h}$ at $37{ }^{\circ} \mathrm{C}$ in a humidified atmosphere containing $5 \% \mathrm{CO}_{2}$ (Mosmann, 1983). After incubation with the extract or fractions, $20 \mu \mathrm{L}$ of MTT at $5 \mathrm{mg} / \mathrm{mL}$ were added. After $3 \mathrm{~h}$ of incubation, DMSO $(100 \mu \mathrm{L})$ was added to each well. The plates were centrifuged for $10 \mathrm{~min}$ at $550 \mathrm{~g}$, and the supernatants were read in a Versamax ${ }^{\circledR}$ microplate reader at $570 \mathrm{~nm}$. A positive control was used to verify the MTT test.

\subsection{Transmission electron microscopy}

L. (L.) amazonensis promastigotes were fixed with $2.5 \%$ glutaraldehyde and $4 \%$ paraformaldehyde in sodium cacodylate buffer $0.1 \mathrm{M}$, pH 7.2 for $60 \mathrm{~min}$ at room temperature. Samples were post-fixed in a solution containing $1 \% \mathrm{OsO}_{4}, 0.8 \% \mathrm{~K}_{3}\left[\mathrm{Fe}(\mathrm{CN})_{6}\right]$ and $5 \mathrm{mM} \mathrm{CaCl}_{2}$ in the same buffer for $40 \mathrm{~min}$ at room temperature and protected from light (Vannier-Santos and Lins, 2001). After washing with cacodylate buffer, the samples were dehydrated in increasing concentrations of acetone and embedded in epoxy resin (Polybed 820, PolySciences). The ultrathin sections were contrasted with $7 \%$ uranyl acetate in $\mathrm{MeOH}$ and aqueous $1 \%$ lead citrate for viewing under a transmission electron microscope (Zeiss EM109).

\section{6. $I C_{50}$ determination and inhibition kinetics}

L. (L.) amazonensis arginase activity was determined as previously described (da Silva et al., 2008; Silva and Floeter-Winter, 2010). To evaluate the inhibitory activity of EE and derived fractions, the tests were performed in a reaction mixture containing recombinant arginase $(10 \mu \mathrm{L})$ from $L$. (L.) amazonensis (equivalent to $30 \mu \mathrm{g} / \mathrm{mL}$ protein) $100 \mathrm{mM} \mathrm{L}$-arginine at $\mathrm{pH} 9.5$ and $70 \mu \mathrm{L}$ of the previously obtained aqueous solution fraction (HF, DF AF-MS and BUF) or $\mathrm{H}_{2} \mathrm{O}$ (positive control). The reaction mixture was incubated at $37{ }^{\circ} \mathrm{C}$ for $15 \mathrm{~min}$.

Arginase activity was determined using the Berthelot enzymatic-colorimetric assay method (Fawcett and scott, 1960), which detects urea production. Briefly, the reaction mixture $(10 \mu \mathrm{L})$ was transferred to R1 (20 mM phosphate buffer, $750 \mu \mathrm{L}$ ), pH 7.0, containing $60 \mathrm{mM}$ salicylate, $1 \mathrm{mM}$ sodium nitroprusside and $>500 \mathrm{IU}$ urease). The R1 mixture was incubated at $37^{\circ} \mathrm{C}$ for $10 \mathrm{~min}$, and R2 $(750 \mu \mathrm{L}, 10 \mathrm{mM} \mathrm{NaOCl}$ and $150 \mathrm{mM} \mathrm{NaOH})$ was added and incubated at $37^{\circ} \mathrm{C}$ for $10 \mathrm{~min}$. Spectrophotometric measurements were performed at $600 \mathrm{~nm}$ using a Hitachi $2810 \mathrm{U}$ spectrophotometer. Control experiments were performed under the same conditions, but in the absence of the inhibitor. $\mathrm{IC}_{50}$ measurements were performed with inhibitor concentrations obtained by the following two serial dilutions: the first set of dilutions contained $1250,125,12.5$ and $1.25 \mu \mathrm{M}$ inhibitor, and the second dilution $250,25,2.5,0.25 \mu \mathrm{M}$ inhibitor. The reaction was performed with $50 \mathrm{mM}$ L-arginine in $50 \mathrm{mM}$ CHES buffer at $\mathrm{pH}$ 9.5. All assays were performed in duplicate on three independent measurements.

\subsection{Antileishmanial susceptibility test}

Promastigote forms of $L$. (L.) amazonensis MHOM/BR/75/Josefa strain were cultured at $26^{\circ} \mathrm{C}$ in Warren's medium (brain heart infusion plus haemin and folic acid) $\mathrm{pH} 7.2$, supplemented with $10 \%$ heat-inactivated fetal bovine serum. Promastigotes from a 48-h-old logarithmic-phase culture were suspended to yield $10^{5}$ cells $/ \mathrm{ml}$, and treated with fractions obtained from crude extracts of C. pachystachya. The fraction concentrations used were 6.25, $12.5,25,50$ and $100 \mu \mathrm{g} / \mathrm{ml}$. Cultures were incubated at $26^{\circ} \mathrm{C}$ for $72 \mathrm{~h}$. The activity of the fraction was evaluated by cell counting using a Neubauer chamber. The antileishmanial activity was expressed as the $\mathrm{IC}_{50}$ (50\% inhibitory concentration) after a $72 \mathrm{~h}$ incubation period. The control experiment was made with solvent used to solubilize the fractions.

\subsection{Data analysis}

For all tests, differences greater than $p<0.05$ were considered significant. Analysis was performed using an ANOVA and a posteriori Tukey's tests by use of Prism 5.0 software (GraphPad). All tests were performed in triplicate with at least three independent repetitions. Inhibition data were analyzed also using the GraphPad Prism 5.0 software.

\section{Acknowledgments}

This research was supported by FAPESP (Fundação de Amparo à Pesquisa do Estado de São Paulo Proc. 2009/08715-3) and Amazon/ Edital MCT/CNPQ/MS-SCTIE-DECIT. E.M.C. received fellowships from $\mathrm{CNPq}$ (Conselho Nacional de Desenvolvimento Científico e Tecnológico), C.C.M. and J.F.L.Jr. received fellowship from Coordenação de Aperfeiçoamento de Pessoal de Nível Superior (CAPES) and MBGR received fellowships from FAPESP.

\section{References}

Ambit, A., Woods, K.L., Cull, B., Coombs, G.H., Mottram, J.C., 2011. Morphological events during the cell cycle of Leishmania major. Eukaryot. Cell 10, 1429-1438.

Aragão, D.M., Guarize, L., Lanini, J., da Costa, J.C., Garcia, R.M., Scio, E., 2010. Hypoglycemic effects of Cecropia pachystachya in normal and alloxan-induced diabetic rats. J. Ethnopharmacol. 128, 629-633.

Astelbauer, F., Walochnik, J., 2011. Antiprotozoal compounds: state of the art and new developments. Int. J. Antimicrob. Agents 38, 118-124. 
Balaña-Fouce, R., Calvo-Álvarez, E., Alvarez-Velilla, R., Prada, C.F., Pérez-Pertejo, Y. Reguera, R.M., 2012. Role of trypanosomatid's arginase in polyamine biosynthesis and pathogenesis. Mol. Biochem. Parasitol. 181, 85-93.

Bergeron, C., Boulet, L.P., Page, N., Laviolette, M., Zimmermann, N., Rothenberg, M.E., Hamid, Q., 2007. Influence of cigarette smoke on the arginine pathway in asthmatic airways: increased expression of arginase I. J. Allergy Clin. Immunol. 119, 391-397.

Birkholtz, L.M., Williams, M., Niemand, J., Louw, A.I., Persson, L., Heby, O., 2011. Polyamine homoeostasis as a drug target in pathogenic protozoa: peculiarities and possibilities. Biochem. J. 438, 229-244.

Bocedi, A., Dawood, K.F., Fabrini, R., Federici, G., Gradoni, L., Pedersen, J.Z., Ricci, G., 2010. Trypanothione efficiently intercepts nitric oxide as a harmless iron complex in trypanosomatid parasites. FASEB J. 24, 1035-1042.

Camargo, E.P., Coelho, J.A., Moraes, G., Figueiredo, E.N., 1978. Trypanosoma spp. Leishmania spp. and Leptomonas spp.: enzymes of ornithine-arginine metabolism. Exp. Parasitol. 46, 141-144.

Castilho-Martins, E.A., Laranjeira da Silva, M.F., dos Santos, M.G., Muxel, S.M., Floeter-Winter, L.M., 2011. Axenic Leishmania amazonensis promastigotes sense both the external and internal arginine pool distinctly regulating the two transporter-coding genes. PLoS ONE 6, e27818

Cavalli, A., Lizzi, F., Bongarzone, S., Belluti, F., Piazzi, L., Bolognesi, M.L., 2010 Complementary medicinal chemistry-driven strategies toward new antitrypanosomal and antileishmanial lead drug candidates. FEMS Immunol. Med. Microbiol. 58, 51-60.

Colotti, G., Ilari, A., 2011. Polyamine metabolism in Leishmania: from arginine to trypanothione. Amino Acids 40, 269-285.

Consolini, A.E., Ragone, M.I., Migliori, G.N., Conforti, P., Volonté, M.G., 2006 Cardiotonic and sedative effects of Cecropia pachystachya Mart. (ambay) on isolated rat hearts and conscious mice. J. Ethnopharmacol. 106, 90-96.

da Silva, E.R., Castilho, T.M., Pioker, F.C., Tomich de Paula Silva, C.H., Floeter-Winter, L.M., 2002. Genomic organisation and transcription characterisation of the gene encoding Leishmania (Leishmania) amazonensis arginase and its protein structure prediction. Int. J. Parasitol. 32, 727-737.

da Silva, E.R., da Silva, M.F., Fischer, H., Mortara, R.A., Mayer, M.G., Framesqui, K., Silber, A.M., Floeter-Winter, L.M., 2008. Biochemical and biophysical properties of a highly active recombinant arginase from Leishmania (Leishmania) amazonensis and subcellular localization of native enzyme. Mol. Biochem. Parasitol. 159, 104-111.

da Silva, E.R., Maquiaveli, C.D., Magalhães, P.P., 2012a. The leishmanicidal flavonols quercetin and quercitrin target Leishmania (Leishmania) amazonensis arginase. Exp. Parasitol. 130, 183-188.

da Silva, M.F.L., Zampieri, R.A., Muxel, S.M., Beverley, S.M., Floeter-Winter, L.M. 2012b. Leishmania amazonensis arginase compartmentalization in the glycosome is important for parasite infectivity. PLoS ONE 7, e34022.

de Toledo, C.E., Britta, E.A., Ceole, L.F., Silva, E.R., de Mello, J.C., Dias Filho, B.P., Nakamura, C.V., Ueda-Nakamura, T., 2011. Antimicrobial and cytotoxic activities of medicinal plants of the Brazilian cerrado, using Brazilian cachaça as extractor liquid. J. Ethnopharmacol. 133, 420-425.

Delarcina, S., Lima-Landman, M.T., Souccar, C., Cysneiros, R.M., Tanae, M.M., Lapa A.J., 2007. Inhibition of histamine-induced bronchospasm in guinea pigs treated with Cecropia glaziovi Sneth and correlation with the in vitro activity in trachea muscles. Phytomedicine 14, 328-332.

Demougeot, C., Prigent-Tessier, A., Bagnost, T., André, C., Guillaume, Y., Bouhaddi, M., Marie, C., Berthelot, A., 2007. Time course of vascular arginase expression and activity in spontaneously hypertensive rats. Life Sci. 80, 1128-1134.

Fairlamb, A.H., Cerami, A., 1992. Metabolism and functions of trypanothione in the Kinetoplastida. Annu. Rev. Microbiol. 46, 695-729.

Fawcett, J.K., Scott, J.E., 1960. A rapid and precise method for the determination of urea. J. Clin. Pathol. 13, 156-159.

Fonseca-Silva, F., Inacio, J.D., Canto-Cavalheiro, M.M., Almeida-Amaral, E.E., 2011 Reactive oxygen species production and mitochondrial dysfunction contribute to quercetin induced death in Leishmania amazonensis. PLoS ONE 6, e14666.

Frantz, S., 2005. Drug discovery: playing dirty. Nature 437, 942-943.

Gaur, U., Roberts, S.C., Dalvi, R.P., Corraliza, I., Ullman, B., Wilson, M.E., 2007. An effect of parasite-encoded arginase on the outcome of murine cutaneous leishmaniasis. J. Immunol. 179, 8446-8453.

Hammarton, T.C., Mottram, J.C., Doerig, C., 2003. The cell cycle of parasitic protozoa: potential for chemotherapeutic exploitation. Prog. Cell Cycle Res. 5, 91-101.

Hampton, T., 2004. "Promiscuous" anticancer drugs that hit multiple targets may thwart resistance. JAMA 292, 419-422.

Heby, O., Persson, L., Rentala, M., 2007. Targeting the polyamine biosynthetic enzymes: a promising approach to therapy of African sleeping sickness, Chagas' disease, and leishmaniasis. Amino Acids 33, 359-366.

Igarashi, K., Kashiwagi, K., 2010. Modulation of cellular function by polyamines. Int. J. Biochem. Cell Biol. 42, 39-51.

Iniesta, V., Gómez-Nieto, L.C., Corraliza, I., 2001. The inhibition of arginase by $\mathrm{N}$ (omega)-hydroxy-L-arginine controls the growth of Leishmania inside macrophages. J. Exp. Med. 193, 777-784.

Iniesta, V., Gómez-Nieto, L.C., Molano, I., Mohedano, A., Carcelén, J., Mirón, C., Alonso, C., Corraliza, I., 2002. Arginase I induction in macrophages, triggered by Th2-type cytokines, supports the growth of intracellular Leishmania parasites. Parasite Immunol. 24, 113-118.

Jun, T., Bochu, W., Liancai, Z., 2007. Hydrolytic cleavage of DNA by quercetin manganese(II) complexes. Colloids Surf. B Biointerfaces 55, 149-152.
Lacaille-Dubois, M.A., Franck, U., Wagner, H., 2001. Search for potential angiotensin converting enzyme (ACE)-inhibitors from plants. Phytomedicine 8, 47-52.

Lima-Landman, M.T., Borges, A.C., Cysneiros, R.M., De Lima, T.C., Souccar, C., Lapa, A.J., 2007. Antihypertensive effect of a standardized aqueous extract of Cecropia glaziovii Sneth in rats: an in vivo approach to the hypotensive mechanism. Phytomedicine 14, 314-320.

Maia, C., Lanfredi-Rangel, A., Santana-Anjos, K.G., Oliveira, M.F., De Souza, W., Vannier-Santos, M.A., 2008. Effects of a putrescine analog on Giardia lamblia. Parasitol. Res. 103, 363-370.

Menezes, D., Valentim, C., Oliveira, M.F., Vannier-Santos, M.A., 2006. Putrescine analogue cytotoxicity against Trypanosoma cruzi. Parasitol. Res. 98, 99-105.

Mittra, B., Saha, A., Chowdhury, A.R., Pal, C., Mandal, S., Mukhopadhyay, S., Bandyopadhyay, S., Majumder, H.K., 2000. Luteolin, an abundant dietary component is a potent anti-leishmanial agent that acts by inducing topoisomerase II-mediated kinetoplast DNA cleavage leading to apoptosis. Mol. Med. 6, 527-541.

Mosmann, T., 1983. Rapid colorimetric assay for cellular growth and survival: application to proliferation and cytotoxicity assays. J. Immunol. Methods 65, 55-63.

Muzitano, M.F., Falcão, C.A., Cruz, E.A., Bergonzi, M.C., Bilia, A.R., Vincieri, F.F., RossiBergmann, B., Costa, S.S., 2009. Oral metabolism and efficacy of Kalanchoe pinnata flavonoids in a murine model of cutaneous leishmaniasis. Planta Med. 75, 307-311.

Odonne, G., Berger, F., Stien, D., Grenand, P., Bourdy, G., 2011. Treatment of leishmaniasis in the Oyapock basin (French Guiana): A K.A.P. survey and analysis of the evolution of phytotherapy knowledge amongst Wayãpi Indians. J. Ethnopharmacol. 137, 1228-1239.

Reguera, R.M., Balaña-Fouce, R., Showalter, M., Hickerson, S., Beverley, S.M., 2009. Leishmania major lacking arginase (ARG) are auxotrophic for polyamines but retain infectivity to susceptible BALB/c mice. Mol. Biochem. Parasitol. 165, 4856.

Reis, I.A., Martinez, M.P., Yarlett, N., Johnson, P.J., Silva-Filho, F.C., Vannier-Santos, M.A., 1999. Inhibition of polyamine synthesis arrests trichomonad growth and induces destruction of hydrogenosomes. Antimicrob. Agents Chemother. 43, 1919-1923.

Riley, E., Roberts, S.C., Ullman, B., 2011. Inhibition profile of Leishmania mexicana arginase reveals differences with human arginase I. Int. J. Parasitol. 41, 545552

Roberts, S.C., Tancer, M.J., Polinsky, M.R., Gibson, K.M., Heby, O., Ullman, B., 2004. Arginase plays a pivotal role in polyamine precursor metabolism in Leishmania. Characterization of gene deletion mutants. J. Biol. Chem. 279, 23668-23678.

Schinella, G., Aquila, S., Dade, M., Giner, R., Recio, M.e.C., Spegazzini, E., de Buschiazzo, P., Tournier, H., Ríos, J.L., 2008. Anti-inflammatory and apoptotic activities of pomolic acid isolated from Cecropia pachystachya. Planta Med. 74 215-220.

Sen, G., Mukhopadhyay, S., Ray, M., Biswas, T., 2008. Quercetin interferes with iron metabolism in Leishmania donovani and targets ribonucleotide reductase to exert leishmanicidal activity. J. Antimicrob. Chemother. 61, 1066-1075.

Silva, E.R., Floeter-Winter, L.M., 2010. Activation of Leishmania (Leishmania) amazonensis arginase at low temperature by binuclear Mn2+ center formation of the immobilized enzyme on a Ni2+ resin. Exp. Parasitol. 125, 152-155.

Tanae, M.M., Lima-Landman, M.T., De Lima, T.C., Souccar, C., Lapa, A.J., 2007. Chemical standardization of the aqueous extract of Cecropia glaziovii Sneth endowed with antihypertensive, bronchodilator, antiacid secretion and antidepressant-like activities. Phytomedicine 14, 309-313.

Tasdemir, D., Kaiser, M., Brun, R., Yardley, V., Schmidt, T.J., Tosun, F., Rüedi, P., 2006. Antitrypanosomal and antileishmanial activities of flavonoids and their analogues: in vitro, in vivo, structure-activity relationship, and quantitative structure-activity relationship studies. Antimicrob. Agents Chemother. 50, 1352-1364.

Tkachenko, A.G., Akhova, A.V., Shumkov, M.S., Nesterova, L.Y., 2011. Polyamines reduce oxidative stress in Escherichia coli cells exposed to bactericidal antibiotics. Res. Microbiol.

Toledo, V.M., Tellez, M.G., Sortibrán, A.N., Andrade-Cetto, A., Rodríguez-Arnaiz, R., 2008. Genotoxicity testing of Cecropia obtusifolia extracts in two in vivo assays: the wing somatic mutation and recombination test of Drosophila and the human cytokinesis-block micronucleus test. J. Ethnopharmacol. 116, 58-63.

Vannier-Santos, M.A., De Castro, S.L., 2009. Electron microscopy in antiparasitic chemotherapy: a (close) view to a kill. Curr. Drug Targets 10, 246-260.

Vannier-Santos, M.A., Lins, U., 2001. Cytochemical techniques and energy-filtering transmission electron microscopy applied to the study of parasitic protozoa. Biol. Proced. Online 3, 8-18.

Vannier-Santos, M.A., Menezes, D., Oliveira, M.F., de Mello, F.G., 2008. The putrescine analogue 1,4-diamino-2-butanone affects polyamine synthesis, transport, ultrastructure and intracellular survival in Leishmania amazonensis. Microbiology 154, 3104-3111.

Vermeersch, M., da Luz, R.I., Toté, K., Timmermans, J.P., Cos, P., Maes, L., 2009. In vitro susceptibilities of Leishmania donovani promastigote and amastigote stages to antileishmanial reference drugs: practical relevance of stage-specific differences. Antimicrob. Agents Chemother. 53, 3855-3859.

Wanderley, J.L., Barcinski, M.A., 2010. Apoptosis and apoptotic mimicry: the Leishmania connection. Cell. Mol. Life Sci. 67, 1653-1659.

WHO, 2011. Leishmaniasis: Magnitude of the Problem. World Health Organization. 